\title{
Relationships with the Alcoholic- Beverage Industry, Pharmaceutical Companies, and Other Funding Agencies: Holy Grail or Poisoned Chalice?
}

\author{
Peter Miller, Thomas F. Babor, Thomas McGovern, \\ Isidore Obot and Gerhard Bühringer
}

\begin{abstract}
Introduction
The ethical dimensions of the relationships among researchers, research organizations, journal editors, and the various industries that profit from addictive substances and behaviors are complicated and extensive. They embrace the individual, institutional, and societal dimensions of ethical reflection. In a way, this chapter is a case study on a grand scale that calls for profound ethical analysis. The forces and interests involved are of necessity interwoven, and researchers are dependent on many funding sources as a mainstay for their research. These will be covered in detail as the chapter unfolds. At the heart of the ethical conversation is an issue of trust for individuals and institutions. Ultimately, there are no simple guidelines to help an investigator decide which funding sources to accept or reject. However, it is vital that researchers go through an ethical assessment to consider the issues involved. In this chapter, we will explore the ways in which different interest groups have influenced the research process before demonstrating the use of the PERIL (purpose, extent, relevant harm, identifiers, link) analysis (Adams, 2007), an ethical decision-making framework
\end{abstract}

\section{How to cite this book chapter:}

Miller, P, Babor, T F, McGovern, T, Obot, I and Bühringer, G. 2017. Relationships with the Alcoholic-Beverage Industry, Pharmaceutical Companies, and Other Funding Agencies: Holy Grail or Poisoned Chalice? In: Babor, T F, Stenius, K, Pates, R, Miovský, M, O’Reilly, J and Candon, P. (eds.) Publishing Addiction Science: A Guide for the Perplexed, Pp. 323-352. London: Ubiquity Press. DOI: https://doi. org/10.5334/bbd.p. License: CC-BY 4.0. 
developed specifically to address ethical decision-making. We will extend this previous work to challenge even this framework by asking whether it is simply enough just to question the intentions of vested interests in their funding of research. We will close by stressing the importance of understanding corporate political activity in the context of how vested interests are capable of undermining evidence-based policy at local, state, national, and international levels.

A high proportion of an active researcher's workload is spent applying for grant income. Successful receipt of grant monies is seen as an independent measure of a scientist's worth to the field. But the successful awarding of research money can occasionally be a "poisoned chalice" because of the problems engendered by an association with a funding agency. Such problems include having commercial or other vested interests set the research agenda, determine the way in which research is conducted, or define when and where research is published. Contracts that might seem reasonable when the cash is being waved under one's nose may prevent entire studies from being published or, even worse, result in selective publication that does not portray the actual findings accurately. These types of experiences can devastate individual researchers, both personally and professionally. From the outset, we want to emphasize that individual researchers cannot deal with these issues alone but need support from senior colleagues, their institutions, professional associations, and academic journals.

\section{A Growing Concern}

In a climate of self-interest, often nurtured by a high regard for an exaggerated form of individualism (which is inimical to the common good), it is difficult to develop a consistent appreciation of the place of trust in research undertakings, as is the case elsewhere in society.

(McGovern et al., Chapter 15).

Concerns about the integrity of the evidence base of addiction science have been raised in a number of forums recently (e.g., Adams, 2007; Babor \& Robaina, 2013; Hall, 2006a; Miller, 2013; Miller et al., 2006; Stenius \& Babor, 2010). Many of the authors expressing these concerns have reminded us that, although safeguards such as ethical review committees and other regulatory agencies are in place, ensuring the integrity of the evidence is an ongoing task that requires an awareness of new players (e.g., energy-drink producers) seeking to influence the evidence base, as well as awareness of new technologies for doing so (Hall, 2006a), such as paid contributions to edited books that look scholarly but often have a hidden political agenda. On the other hand, there have been strong developments in the study of such industries and the way in which they use research to muddy the waters of evidence and influence the political process (Hawkins \& Holden, 2014; Savell et al., 2014). This will be discussed later in the chapter in regard to assessing the purpose of industry-funded research. 
Miller et al. (2006) highlighted the influence that major funding bodies (e.g., pharmaceutical companies and governmental departments) can have on research findings and the information-dissemination process. This was considered important from two angles: (a) keeping true to the ideal of science and (b) adhering to the ethical principle of beneficence (Chapter 15). Maintaining the ideal of science was seen as essential for the field, in terms not only of sustaining public trust (as mentioned above) but also of ensuring that the field moves toward the most-effective interventions available. Adhering to the ideal of beneficence (the obligation to maximize possible benefits and minimize possible harms) was viewed as equally important when considering whether research (which may be censored, be partially reported, or go unpublished) could truly be said to be in the best interests of the research participants.

The debate within academic journals and subsequent commentaries has added substantially to our knowledge of how funding bodies influence research both directly and indirectly (Adams, 2007; Ashcroft, 2006; Babor, 2006; Babor \& Miller, 2014; Hall, 2006a, 2006b; Hough \& Turnbull, 2006; Khoshnood, 2006; Lenton \& Midford, 2006). The observations collected from various authorities and presented in Box 16.1 highlight some of the main issues and point to

"Because ... research may adversely affect the reputations of governments and government departments, 'project management' has become an increasingly central part of contractual arrangements between researchers and funders" (Hall, 2006b, p. 240).

" $[\mathrm{I}] \mathrm{n}$ the current funding climate, universities and research centres have incentives not to adhere rigorously to these norms" (Ashcroft, 2006, p. 238).

"In recent years almost all [Australian] state and federal funded drug education research has been commissioned according to funder specifications, rather than being investigator driven" (Lenton \& Midford, 2006, p. 244).

"Certainly, too, government departments set research agendas-and specify research methodologies to suit their own interests, rather than to contribute in a disinterested way to the body of knowledge that relates to policy issues. Government departments do not intentionally commission research that will embarrass their ministers" (Hough \& Turnbull, 2006, p. 242).

"Senior academic researchers should be prepared to 'out' funding bodies for bad behaviour. Researchers with seniority and the protection afforded by tenure should be prepared to protect junior researchers and advocate for an unencumbered right to publish research results" (Hall, 2006b, p. 240).

Box 16.1: Observations about research funding from different commentators. 
the fact that influences on the research process go far beyond industry-related funding bodies alone.

\section{Types of Adverse Influence}

Miller et al. (2006) identified five major avenues through which funding bodies can regulate research in an adverse way: (a) direct censorship (where material is edited or dissemination is interfered with), (b) limiting access to data (either affecting some point or to be used as coercion for favorable interpretation), (c) ongoing funding insecurity (attaching conditions to subsequent funding if previous findings have been awkward or unwelcome), (d) using under-qualified or easily-influenced researchers (which allows funders to control the quality of investigation being carried out, even before the research has commenced), and (e) setting research agendas or dilution (whereby decisions are based on the political, financial, or ideological interests of the funder). For example, pharmaceutical companies overemphasize studies that examine the efficacy of pharmacotherapeutic solutions to drug-related problems, which could make the evidence base appear to be overly favorable for such an intervention (Wagner \& Steinzor, 2007). Other authors (e.g., Gruning et al., 2006; Kassirer, 2005) have provided similar, although slightly different, descriptions of the ways in which interest groups have influenced health policy and scientific research (Box 16.2).

\section{The Tobacco Industry}

The best known example of the way a funding body can act to undermine research integrity and muddy the waters surrounding a topic of public health interest is the concerted campaign by the tobacco industry first to deny the links between smoking and lung cancer and then more recently to support programs that attribute responsibility to the individual smoker rather than to the tobacco companies.

Investigations into tobacco companies continue to identify new ways in which the industry seeks to encourage smoking and at the same time divest itself of responsibility for the subsequent health costs (Drope et al., 2004; Iida \& Proctor, 2004; King, 2006; Muggli et al., 2004; Ong \& Glantz, 2000). There are numerous examples of how tobacco companies have acted to undermine or adulterate health initiatives. The tobacco industry has been found to influence research using every one of the techniques discussed earlier (e.g., Hirshhorn et al., 2001; King, 2006). According to one authority, "perhaps research grants coming from tobacco companies should carry their own Surgeon General's warning. Caution: Tobacco industry sponsorship may be hazardous to the public's health" (Parascandola, 2005, p. 549). 
Gruning and colleagues (2006) identified five ways in which the tobacco industry in Germany distorted science:

- Suppression, through actions such as closing the German Industry Research Institute (which it funded) when its head published results unfavorable to the industry and having subsequent scientists in its employment guarantee that unfavorable results would not be published;

-Dilution, through selective funding of research and the recruitment of scientists who had doubts about the adverse health effects of smoking or whose previous work had found no links, as well as funding research projects designed to find no association between smoking and disease (e.g., Wander \& Malone, 2006);

- Distraction, by selecting and supporting a large number of "confounder studies," which are research projects aimed to distract attention from smoking by investigating other potential causes of smoking-related diseases;

- Concealment, using third-party scientists whose connection to the industry was hidden to increase the credibility and impact of the studies published; and

- Manipulation, the vetting of articles and presentations by the industry before publication or presentation.

Box 16.2: The tobacco industry in Germany.

Source: Gruning et al. (2006).

One example of this is the tobacco industry's support of scientific research and their use of academics as expert witnesses in court cases. As many senior researchers in the addiction field are occasionally asked to serve as expert witnesses for a defendant or a plaintiff, it is instructive to examine cases where such testimony could have implications for public health, especially when it proves to be wrong. Can direct payment of a scientist bias that person's opinions and even sworn testimony in a court case?

Until 1998, most of the tobacco industry funding for research on nicotine and tobacco came through Council for Tobacco Research (CTR) and the Center for Indoor Air Research (CIAR). These two organizations were established and maintained by funding from the tobacco industry. They played a central role in the lawsuits brought against the tobacco industry in the 1990's, when it was found that industry-funded research contradicted the conclusions of independent scientists (Shick and Glantz, 2007). A US judge presiding over two state cases described CTR as "nothing but a hoax created for public relations 
purposes with no intention of seeking the truth or publishing it." (Janson, 1988). The Master Settlement Agreement (MSA) in 1998 dissolved the CTR and CIAR, as they were implicated in a conspiracy of massive fraud. Tobacco companies also agreed to pay $\$ 206$ billion over the first twenty-five years of the agreement to compensate the States for taxpayer money spent for health-care costs connected to tobacco-related illness.

In a series of court cases and depositions, then Professor Emmanuel Rubin testified that the research conducted by the CTR was of high scientific quality and that its scientific review adhered to widely recognized scientific standards. For example, in 2000 testimony for Philip Morris Inc. (p. 29) he stated:

"In my opinion the Council for Tobacco Research was an affective (sic), efficient, generous and thoroughly honest organization that provided funds for excellent biomedical research. It acted in an independent fashion that was no different from other agencies that provided grants. I think that the research that was funded by CTR contributed significantly to understanding the issues of tobacco and health. And, for that reason, I have no objections to funding by the CTR."

Box 16.3 provides excerpts taken from Dr. Rubin's deposition in 2000 during a case brought by a health insurance company against Philip Morris for the costs connected to tobacco smoking. The line of questioning begins with questions of financial payments received by Dr. Rubin. It then continues to explore Dr. Rubin's opinions about the qualifications of members of the Scientific Advisory Board who were senior executives of RJR Tobacco Company, and the practice of having grant applications screened initially by industry lawyers before they were submitted for scientific review. Given the outcome of the trial, Dr. Rubin's testimony provides a good example of how financial COIs may influence the opinions of scientists who serve as expert witnesses.

\section{The Alcohol Industry}

Using terms of justification such as "corporate social responsibility" and "partnerships with the public health community," the alcoholic-beverage industry (mainly large producers, trade associations, and "social-aspects" organizations) funds a variety of "scientific" activities that involve or overlap with the work of independent scientists using techniques that range from efforts to influence public perceptions of research to the direct commissioning of research that is consistent with their public-relations priorities (Babor \& Robaina, 2013).

There are at least three organizations funded predominantly by alcoholindustry sources for the primary purpose of conducting scientific research on alcohol: the European Research Advisory Board, the ABMRF/The Foundation for Alcohol Research, and the Institut de Recherches Scientifiques sur 
$\mathrm{Q}^{*}$. It appears to me that you've given deposition testimony in six smoking and health litigations and have given trial testimony in one. . . . . Can you give me an estimate on how much money you have been compensated for performing as an expert witness in the various tobacco and health litigations in which you have done so?

$A^{*}$. I haven't kept records and that is for, you know, all of this time. I'm not in business, but I'd estimate all of those things, $\$ 500,000, \$ 600,000$.

Q. Over a six year period?

A. Yes.

Q. Dr. Rubin, you just testified that it would not be proper for the president of CTR to send grant applications to CTR's lawyers for legal review solely on the basis of the fact that the research-called for could implicate cigarette smoking as a cause of human disease, correct?

If you were shown evidence that that, in fact, did happen, would that change any of the expert opinions that you've expressed in your expert report?

A. Well, I'd like to know the circumstances...

Q. Did your opinions change if you were shown evidence to indicate that this was a continuing, regular practice, at CTR?

A. You would have to show me the evidence.

${ }^{*}$ Q. refers to questions asked by attorneys for Blue Cross and Blue Shield of New Jersey (Plaintiffs). A. refers to answers provided by Dr. Rubin, expert witness for Philip Morris, Inc.

Box 16.3: Excerpts from Dr. Emmanuel Rubin's Testimony in Blue Cross and Blue Shield of New Jersey vs. Philip Morris, Inc.

Source: Blue Cross and Blue Shield of New Jersey, et al., Plaintiffs, vs. Philip Morris, Incorporated, et al., Defendants. Case no. 98 CIV 3287 (JBW) Videotaped deposition of Emanuel Rubin, M.D., April 12, 2000, Bates Number: 522994762-522994916. pp 47; 110-111. Available at http://industrydocuments. library.ucsf.edu/tobacco/docs/yqnk008347. 
les Boissons. Although some consider the operations of these organizations as a model of the way industry should contribute to alcohol science, questions have been raised about the way they operate and their influence on the scientific process (Babor \& Robaina, 2013). For example, the Institut de Recherches Scientifiques sur les Boissons commissions its own studies in addition to funding investigator-initiated projects, thereby increasing the possibility that industry-favorable topics are promoted. It has also been suggested that a scientist's objectivity might be compromised by receipt of the honoraria and travel funds involved, as well as through the opportunities to fraternize with industry executives at international meetings. Each of these organizations also funds research on industry-favorable topics such as the health benefits of moderate drinking, which then are used as a part of the marketing strategies by the wine and beer industries or as reasons why regulation and taxation should not be imposed on the alcohol industry (Stenius \& Babor, 2010).

In addition to indirect support of research through third-party organizations, there have been several instances in which individual alcohol producers or industry-supported social-aspects/public-relations organizations provide direct support to university-based scientists engaged in alcohol research. The most-notable examples include the Ernest Gallo Clinic and Research Center established by the Gallo Winery at the University of California to study basic neuroscience and the effects of alcohol on the brain; Anheuser-Busch's support of social norms research at seven U.S. universities; and a research center on youth binge drinking funded by Diageo Ireland, part of Diageo PLC, the world's largest producer and distributor of alcohol (Babor, 2006; Babor et al., 1996).

Little is known about the internal marketing research conducted by the alcohol industry and contract research organizations because the information is not shared with the public, the scientific community, or public health professionals. In the case of tobacco, previously secret internal industry documents have revealed that independent analysis of research on sensory perception was used to inform product design for targeted segments of the cigarette market, including young adults (e.g., Carpenter et al., 2005), and there is evidence that the alcohol industry does similar research (Babor, 2009). Contract research requires the services of social and behavioral scientists; therefore, it may pose ethical problems to the extent that such research could facilitate the marketing of products (e.g., alcopops) that are misused by vulnerable populations.

These kinds of funding initiatives not only have the potential for competing interests, but they may also affect the objectivity of independent scientists and the integrity of science. At best, the scientific activities supported by the alcohol industry provide financial support and small consulting fees for basic and behavioral scientists engaged in alcohol research. At worst, they confuse public discussion of health issues and policy options, raise questions about the objectivity of industry-supported alcohol scientists, and provide industry with a convenient way to demonstrate "corporate responsibility" in its attempts to avoid taxation and regulation (see Box 16.4 for further examples of industry activities). 
ICAP is an industry-funded, social-aspects/public-relations organization located in Washington, D.C., USA. It was founded in 1995 by a consortium of alcohol companies, including MillerCoors, which at that time was part of tobacco giant Phillip Morris. According to an article on the early history of ICAP (Jernigan, 2012), MillerCoors's primary interests in the creation of ICAP were purely commercial, that is, to aid their planned international expansion by managing worldwide issues and thereby assisting their sales and marketing group in an increasingly competitive marketplace.

Despite ICAP's original mission to promote understanding of the role of alcohol in society and help reduce the abuse of alcohol worldwide, there is strong evidence that ICAP has evolved primarily into an industry publicrelations organization dedicated to the advancement of industry-favorable alcohol policies (Anderson \& Rutherford, 2002; Babor \& Robaina, 2013; Bakke \& Endal, 2010; Foxcroft, 2005; Jernigan, 2012; McCreanor et al., 2000; Room, 2005). For example, ICAP sponsored conferences and governmental consultations in a number of African countries in which industry-invited representatives helped governmental officials draft national policy plans for their countries. In one analysis of this initiative (Bakke \& Endal, 2010), the national plans-ostensibly designed to fit the specific needs of four different African countries-were found to be virtually identical, with all documents originating from the MS Word document of a senior executive of SABMiller, one of the ICAP's funders.

There is also evidence that ICAP-supported research is of poor quality and is biased in favor of industry positions supporting alcohol education over more-effective alcohol policies (Babor \& Xuan, 2004). ICAP also pays scientists to edit and write chapters for commissioned books that have been criticized for their bias toward industry-favorable positions on alcohol policy (Caetano, 2008; Stimson, et al., 2006).

Any pretense of ICAP's objectivity and independence was abandoned in 2014 with their announced merger with the Global Alcohol Producers Group, a major industry lobby organization. With this merger, ICAP was renamed the International Alliance for Responsible Drinking (IARD). Since its inception in 2005, the Global Alcohol Producers Group has spent more than USD\$1.15 million on lobbying the World Health Organization (OpenSecrets.org, 2015), taking positions that seem to be diametrically opposed to those recommended by the international public health community.

Box 16.4: The research pedigree of the International Center for Alcohol Policies (ICAP), now called the International Alliance for Responsible Drinking (IARD). 


\section{The Pharmaceutical Industry}

The pharmaceutical industry has become more interested in the discovery and evaluation of medications that can be used for the treatment of addiction, including opiate-substitution therapies and nicotine-replacement therapies. As such, pharmaceutical companies represent a different type of research funder from those, such as the tobacco industry, who sell dangerous consumables. The pharmaceutical industry commissions and funds legitimate research that has genuine benefit for the treatment of substance-related disorders. However, this industry also produces psychotropic substances like analgesics, hypnotics and sedatives. They are helpful treatment options when adequately prescribed but there is also increasing concern about prescribed and over-the-counter nonmedical use of these substances, caused by aggressive marketing and inadequate prescriptions by primary care doctors. Examples include the dramatic increase of prescribed opioid analgesics in Canada and the United States, leading to severe negative health consequences and premature death (Fischer et al., 2011; Fischer et al., 2013), or the fact that in many western countries the number of substance use disorders for these classes of drugs is as high as the number of alcohol use disorders (e.g. for Germany: Kraus et al., 2013)

Pharmaceutical companies are as profit driven as the tobacco and alcohol industries and have demonstrated a willingness to engage in such activities as suppression, through delayed or nonpublication of null or negative findings, and dilution, through the selective funding of certain types of research (Kassirer, 2005). There is also evidence that some industry-supported research is biased (Brennan et al., 2006; Kassirer, 2005; Singer, 2008). In an interesting case study that combines pharmaceutical companies and tobacco, Etter et al. (2007) assessed whether the source of funding affected the results of trials of nicotinereplacement therapy for smoking cessation. They found that, compared with independent trials, industry-supported trials were more likely to produce statistically significant results and larger odds ratios.

In general, it has been found that researchers who report a financial competing interest are more likely to present positive findings (Friedman \& Richter, 2004). Such behavior has not been documented within the addictions field, although medications used by many addicted patients for other complaints such as depression and anxiety have been the subject of controversial research practices.

\section{The Gambling Industry}

Problem gambling has been strongly linked to a range of personal and social problems (Gupta \& Derevensky, 1998). The opportunities for addiction scientists to receive funding from gambling-industry sources have increased 
significantly over the last decade, raising a number of ethical and organizational risks similar to those associated with accepting funding from other dangerous consumption industries (Adams, 2007).

As in the case of relationships with the tobacco and alcohol industries, relationships with social-aspects/public-relations organizations have been used to mitigate potential negative associations with gambling problems and to give the impression either that the activity leads to public good or that they have at least attempted to rectify potential harm (Adams \& Rossen, 2006). In countries such as Australia and New Zealand, a governmental or quasi-governmental agency has been created to manage voluntary funds in a way that appears independent of the source. Adams and Rossen point out that the major problem with such arrangements "is the perception that donor organizations should still retain a significant say in how the money is used" (p. 11). This culture leads to uncritical acceptance of gambling-industry perspectives and misrepresents the industry's willingness to trade profits for public health. This has meant in the past that industry officials were "consistently instrumental in ensuring that activities that might threaten the consumption of gambling were unlikely to receive significant funding (this particularly applied to research, health advocacy, and public health initiatives)" (Adams \& Rossen, 2006, p. 12). This may explain why there have been few studies of the role of the gambling industry in the promotion of gambling behavior and pathological gambling.

It has been proposed that government-mandated contributions provide an alternative option to support research and provide a way to mollify criticism. In this arrangement, governments enact legislation that requires gambling providers to allocate a portion of their net income to projects, including research, with a community purpose. The major difficulty with this arrangement is the risk of increasing financial dependency, leading scientists to avoid criticizing gambling interests (Adams \& Rossen, 2006). Likewise, the responsibility of governments to regulate gambling and prevent gambling problems may be compromised by the possibility that governments have themselves become "addicted" to the tax revenues derived from gambling.

\section{Governmental Agencies}

Albert Einstein (1934) once said that the "pursuit of scientific truth, detached from the practical interests of everyday life, ought to be treated as sacred by every government, and it is in the highest interests of all that honest servants of truth should be left in peace." Einstein's plea, directed at the fascist government of Mussolini, has been honored by most government funding agencies, but there are many cases in which the interests of government are prioritized over scientific pursuit of truth. In a situation similar to that of the pharmaceutical companies, national and international 
governmental bodies fund many valuable research studies. However, as seen in earlier examples, research has sometimes been used to achieve political or financial goals, such as supporting current budget allocations, protecting policy makers who have made bad decisions, or undermining more-effective strategies because they are unpopular and politically risky. Miller et al. (2006) identified two examples in which governmental funders acted to distort research findings in Australia and the United Kingdom, particularly regarding more-controversial activities such as needle and syringe programs. Similar observations have been made about the difficulty in obtaining funding for research into the effectiveness of needle and syringe programs and other forms of harm reduction in the United States (Pollak, 2007; Small \& Drucker, 2006;).

\section{Other Funding Agencies}

Increasingly, charitable organizations such as the Robert Wood Johnson Foundation in the United States, the Joseph Rowntree Foundation in the United Kingdom, and the Millennium Trust in Australia have taken on agenda-setting roles that include research. Although most do not have profit imperatives akin to those seen in the tobacco, alcohol, and pharmaceutical industries, some nonetheless have their own agendas, and only a worthy few use transparent peer review. For example, the Wates Foundation in the United Kingdom has previously funded only research that supports abstinence-only approaches. Nepotism and personal competing interests can also come into play when trustees back projects supported by their friends or projects in which they are personally involved. This lack of peer review and external accountability means that such organizations may end up skewing the evidence base by supporting research into only certain types of intervention. Although some of this might be balanced by different foundations having different interests, the reality is that these funders have the potential to, at times, favor ideologically and politically simple and popular interventions. For example, although a small number of trusts, such as the Soros Foundation, have funded research into harm reduction and drug-policy reform, there are many more foundations that will fund only abstinence-based programs or programs aimed at abstinence, such as education programs. Although there are many reasons for this, most revolve around trustees not being knowledgeable about the available evidence and theory. In addition, many trustees and directors are politically aware individuals who are in the public spotlight. They may be reluctant to become associated with politically sensitive topics. All of this means that researchers should be aware of the possible consequences of applying for funding from such organizations, because even limited research might contribute to the overall publication bias in the field. 


\section{Other Interest Groups}

Funding bodies are not the only groups to control research findings. For instance, Hall (2006b) identified the possibility of drug-user groups and socially conservative members of ethics committees prioritizing their own interests at the expense of the integrity of the research. Members of ethics committees hold very powerful positions when it comes to rejecting, delaying, or modifying research proposals. Although most declare financial competing interests, ideological positions are different, and indeed many would not identify strongly held beliefs as being competing interests. For example, individual members of ethics committees who are strongly attached to abstinence-only programs may block or delay research into controlled-drinking interventions in the belief that they cannot be morally justifiable.

There is also substantial room for competing interests inherent in the current peer-review framework (Hall, 2006a). With increasing competition over scarce resources, editors or reviewers may thwart the publication of research articles that counter their own theories or may thwart the publication of findings of their major competitors for funding. Although some journals have begun to publish ethical statements for editors, similar statements for reviewers of articles and funding applications may soon be required. Similarly, we should not forget that most researchers have their own pet theories, which can result in skewed research findings, particularly when those theories align with the interests of others such as professional societies, governments, or industry bodies. As noted in Chapter 14, these kinds of competing interests are difficult to detect, but they should nevertheless be considered by authors when evaluating their own work.

Other social groups that might seek to influence research include professional associations, fellowship groups, religious organizations, and even service providers. Professional associations (e.g., medical societies) have traditionally sought to maintain or increase their influence regarding any number of areas of knowledge and practice (Willis, 1989). Each discipline produces its own literature base. The size and complexity of this literature base helps to determine differential power structures within treatment settings. In the alcohol and drug sector, medicine and psychiatry (with the support of the pharmaceutical industry) dominate the literature base, resulting in the medical model (and pharmacotherapies) having the strongest evidence base. In a different type of influence, some fellowship groups may influence research findings through nonparticipation (e.g., Wilton \& DeVerteuil, 2006).

Service providers are also not disinterested parties. Almost all (with a few notable exceptions) derive their income (and some of their raison detre) from treating addiction. This has substantial implications for the politics of treatment and the vested interests many people bring to the research enterprise. The political and economic weight of mantras such as "treatment works" bear little 
relation to the complex evidence base and far more to the pragmatic needs of governments and service providers. Although many service providers use the discourse of charitable objectives, they are invested both financially and existentially in the perceived success of the treatment they provide. This raises substantial ethical issues when conducting program-evaluation research in treatment settings, especially if the evaluation is funded by the service provider or its funding body. Ethical considerations such as the true reporting of findings (even when negative), full editorial control of research projects, and the assurance of adequate dissemination should be negotiated before research commences. Such issues require that researchers, reviewers, and journal editors within the field apply a strong critical gaze to research and encourage an ethos of independence, even when such independence may not be economically prudent.

\section{Funding Issues in the Developing World}

All of the examples discussed thus far describe the situation in the developed world. However, the issues facing researchers in the developing world are likely to be even more complicated and are much less likely to be documented. As do their counterparts in the more-developed parts of the world, researchers in developing countries face many challenges in their work. In both environments, success is tied to the availability of resources and the overall intellectual climate (Adair, 1995). Significant achievements as a scholar in a university or research institute require the ability to attract funding for research and to publish research findings, preferably in journals of high repute. Although the expectations from employers and the public might be the same, both activities are not always easy to execute by scholars in poor countries in which there are virtually no local resources for research.

When asked about the major problems encountered in their work, researchers and service providers affiliated with drug-demand-reduction organizations in Nigeria not surprisingly identified lack of funding as the leading challenge (Obot, 2004). Indeed, it is a rare country in Africa and other low-income parts of the world in which one can find consistent and near-sufficient outlay for scientific research on any topic, including addiction and other public health issues. This is especially the case for researchers in countries that constitute the "bottom billion" (Collier, 2007) or countries often described as least developed. In addition, competing for scarce resources with colleagues who are in resource-rich countries is often an impossible challenge. For the enterprising researcher, the response to this dearth of local funding opportunities is to conduct self-sponsored research (with all the limitations that this entails) or seek support from less-competitive external sources. This situation provides a good opportunity for organizations with ideological positions to propagate their interests and for others with economic interests to gain a foothold through financial support for research and training in these countries. 
This is a potential source of danger for research in many developing countries and one that has not received sufficient attention. Although there has been active discussion about unfair distribution of benefits of international research, especially coming from concerns about the ethical dimensions of clinical trials in developing countries (e.g., Bhutta, 2002), the exploitation that is implicit in some sources of funding for research in developing countries deserves greater scrutiny. Exploitation is more likely to occur in situations in which there is little understanding of competing interests, low economic capacity, limited infrastructure, and lack of ethical oversight-all of which are conditions that characterize many low-income countries.

In the field of alcohol research, developing countries are experiencing a growing interest by representatives of the alcoholic-beverage industry masquerading as social-aspects organizations and seeking partnerships with researchers and policy makers. Usually the amount of money involved is a fraction of what would be spent for similar efforts in western countries, but it goes a long way for the scholar to whom such support is a lifeline, enabling research and the publication of a book with an international imprint. In Africa, for example, the International Center for Alcohol Policies (ICAP; Box 16.3 above) has provided support for data collection, write-up, and publication of work with the potential of influencing local alcohol policy (e.g., Haworth \& Simpson, 2004). For the funding organization, association with (usually) a high-profile academic or policy expert in a developing country validates their professed selfless motives. This can be a particularly pernicious strategy, because the developing-country scholar who has been co-opted by the alcohol, tobacco, or pharmaceutical industry might be the same scholar on whom government depends for advice when needed.

It is not always lack of financial resources that drives the accommodation to untested imported theories and practices. Sometimes it is lack of knowledge, or even naïveté. A researcher in a developing country might find it difficult to suspect the motives of a funding agency that is acceptable to that country's government and one that is supported or led by internationally recognized academics or professionals. To guard against establishing or sustaining relationships with funding agencies that might lead to bad science or bad policy, it is important for researchers in developing countries to be more skeptical of easy money by questioning its source and the motives of its providers. That is easier to do today than it might have been 10 years ago, because most of the time all the information that is needed to decide whether to take the money can be found on the Internet.

\section{Competing Interests: What are They, Why are They Important}

As suggested by the examples reviewed above, funding sources can influence scientific integrity in a variety of ways, ranging from subtle bias in the way 
research findings are presented to outright distortion of the research agenda or the scientific literature. One way to approach the ethical implications of many of the issues raised in this chapter is through the concept of competing interests. Competing interests can be financial, personal, ideological, political, and academic. A competing interest does not in itself constitute wrongdoing; rather, it acknowledges that the researcher has an interest that may be put above the integrity of the research being conducted. It is only the failure to declare real or potential competing interests to an editor, one's co-authors, and the readers of an article that constitutes scientific misconduct. Potential competing interests are very important when it comes to the ability of the reader to assess the validity of any piece of scientific work. As noted above and in Chapter 14, competing interests may take many forms. For example, the issue of ideological bias has been raised as a possible competing interest in medical research. A series of articles and responses about prayer as medicine has raised substantial concerns about the interface between faith and science (Clarke, 2007; Jantos \& Kiat, 2007). It has been suggested that "for the benefit of a secular readership, in articles concerning religion and medicine in the Journal, the Editor should require the authors' religious position to be stated under 'competing interests"' (Clarke, 2007, p. 422).

\section{How to Avoid Competing Interests and Other Threats to Scientific Integrity and Academic Freedom}

Just as there are many forms of competing interests, so too are there many different ways to avoid or reduce undue influence, although many commentators believe that none of the possible options is entirely satisfactory or risk free (Adams \& Rossen, 2006). By far the most commonly proposed way to avoid or ameliorate competing interests is through communication with one's peers, particularly when done alongside ethics-awareness exercises (e.g., White \& Popovits, 2001). Adams (2007) recommends that individuals, organizations, and others involved with interested parties engage in processes that raise ethical consciousness in conjunction with transparent regulatory frameworks that ensure accountability and independence from organizations and governmental and professional associations. This kind of communication and awareness raising has begun to occur at a number of levels.

Recently, the institutions responsible for the production and dissemination of research (i.e., journals, professional societies, and academic institutions) have taken some important initiatives. Academic journals have increasingly begun to enact competing interest strategies including (a) requiring author statements that declare funding source, which are then published with the article; (b) a positive statement that all authors had complete control over the research process; (c) reviewer and editor statements similar to those of authors; and (d) prior registration with an approved clinical-trials register as a prerequisite 
for publication. Journal editors have also begun to look at strategies for assessing publication bias within their journals and at a more general level. Some journals have used their editorial pages to name and shame parties that behave inappropriately (e.g., Edwards et al., 2005) and to educate the scientific community about the need for competing interest policies (Babor \& Miller, 2014).

Professional associations have begun to draw up guidelines regarding the behavior of acceptable funding bodies, competing interests, and related issues. For example, the Federation of American Societies for Experimental Biology (2007) has issued a call to the scientific community to adopt more-consistent policies and practices for disclosing and managing financial relationships between academia and industry in biomedical research. The Federation of American Societies for Experimental Biology Toolkit (Federation of American Societies for Experimental Biology) consists of a set of model guidelines that speaks specifically to institutions that develop and enforce policies for their investigators, editors who develop disclosure policies for authors, and scientific and professional societies that have a role in promoting professional ethics. Similarly, the RESPECT Code of Practice (Dench et al., 2004) is a voluntary code of practice regarding the conduct of socioeconomic research. The proposed guidelines are a synthesis of several professional and ethical codes of practice designed to protect researchers from unprofessional or unethical demands. In one of the most thorough policy statements on the subject of competing interests, the International Network on Brief Interventions for Alcohol and Other Drugs issued a position statement that is summarized in Box 16.5.

(1) INEBRIA believes that the commercial activities of the alcohol industry pose a conflict of interest of such magnitude that any form of engagement with the alcohol industry may influence its independence, objectivity, integrity, and credibility internationally.

(2) All individuals wishing to present at an INEBRIA meeting will be required to complete a conflict-of-interest declaration for the work being presented.

(3) Members of the coordinating committee will sign a conflict-ofinterest declaration and may not have worked with or received funding from the alcohol industry, directly or indirectly, in the five years before their election date or during their term of office.

Box 16.5: Summary of the International Network on Brief Interventions for Alcohol and Other Drugs (INEBRIA) Position Statement on the Alcohol Industry. 
Institutions such as universities and research centers have developed policies regarding acceptable funding bodies, and some scrutinize research contracts for possible competing interests. A growing number of universities (e.g., Kings College London) have refused to accept funding from the tobacco industry, and some research centers have developed their own internal policies (Box 16.6). Deakin University (Australia) now prohibits the receipt of research funding from the tobacco and gambling industries, as well as social, health or epidemiological research funded by the alcohol industry. There is also scope for institutional ethics review boards to assess the appropriateness of funderresearcher relationships. Questions regarding such relationships are now incorporated in the Australian National Ethics Application Form (www.nhmrc.gov. $\mathrm{au} /$ health-ethics/human-research-ethics-committees-hrecs/hrec-forms/neafnational-ethics-application-for). Such responses are designed to support individual researchers in the decision-making process and provide more-reliable and consistent approaches to this complex issue (Babor \& McGovern, 2007; Miller et al., 2006).

However, resolving these issues remains in large part the responsibility of individual authors, many of whom have a limited ability to understand or act upon the complex ethical, political, clinical, and scientific issues surrounding the initiatives coming from a particular funding source. Fortunately, most addiction scientists have chosen to eliminate themselves from participation in activities with obvious competing interests, such as consulting arrangements with the tobacco and alcohol industries and restrictions from funding sources that prevent them from retaining ownership of data and the investigator's right to publish it (Babor \& McGovern, 2007). Nevertheless, what is needed is a more-systemic set of procedures that allows individuals to conduct a risk analysis of different funding opportunities.

\section{Decision-Making Approaches}

Several approaches have been suggested to guide decision making by independent scientists when they consider collaboration with the alcoholic-beverage industry and other dangerous consumption industries (Babor, 2009; Babor \& McGovern, 2007; Stenius \& Babor, 2010). Decisions regarding collaboration with bodies that may seek to influence research can range from a "hands-off" position to full collaboration. Adopting a hands-off position, in which members of the scientific community and their organizational sponsors refuse to engage in communication or collaboration with industry representatives, is based on the assumption that commercial interests are incompatible with the values and aims of public health in general and with health-related scientific research in particular. Some have argued that the main effect of industry's recent cooperation with scientists and public health professionals has been to improve their corporate image with the public and with governmental policy 


\section{Dealing with Possible Competing Interests Related to the Financing of Our Research Projects}

The proportion of industry research funding within the financial budget of the institute has been very low since the foundation of the IFT Institut für Therapieforschung in 1973. But caution is needed, because this part of research support is provided by organizations and companies that produce or distribute psychoactive substances (e.g., alcohol or pharmaceutical industry) or are active in the gambling business (including gambling companies licensed or owned by the German States) and because of the internationally known incidents of scientific misconduct.

The IFT does not reject funding of research by commercial institutions in principle but is aware of the particular responsibility in this area. In times of short or even declining public research funding and direct demands of the public to cooperate with industry and to expand commercial third-party funds for research, it is hardly possible to abandon such sources of funding in principle. The institute has in this context the following rules:

- Research requests to conduct a study on a given research question will be accepted only if (a) the research question is formulated globally and is undirected (e.g., the extent of drug abuse in the population) and not biased (e.g., the study is not expected to demonstrate that a certain medicine bears no risk for the population), (b) the research question is scientifically relevant, and (c) the free and unrestricted further design of the study is guaranteed.

- A further precondition for accepting funding by industry sources is the guaranteed independent formulation of the research objectives, hypotheses, and study methodology, and the unrestricted statistical analysis, interpretation, and publication of results. The funds have to be granted to the IFT as unrestricted educational grants or donations.

- We do not accept funding of research projects by the tobacco industry (reasons: evidence of long-lasting, one-sided, and unacceptable manipulation of scientists and scientific results).

- A single funding source must not contribute to more than $10 \%$ of the annual budget, and all industry funds should not exceed $20 \%$. It is notable that these limits have never been reached: The average contribution is about $2 \%$, and it has never exceeded $5 \%$ in the past.

- All results will be published.

- Lectures given in the context of industry organizations are accessible via the website of the IFT. 


\section{Funding in the "Gray Area" between Public and Commercial Organizations}

Examples are charitable organizations, (nonprofit) health insurance companies, and industry associations. In most cases, these organizations are accountable to the public or the commercial sector. The IFT applies in each case the same rules as for commercial organizations.

Box 16.6: One research institution's guidelines on acceptable research funding. Source: Institut für Therapieforschung, München, Germany (www.ift.de).

makers, rather than to promote science (Babor \& Robaina, 2013; Gmel et al., 2003; McCreanor et al., 2000; Munro, 2004).

The other end of the spectrum is to engage in dialogue with industry representatives, accept industry funding for research, and participate as "partners" in industry-funded scientific activities such as the publication of books (e.g., Stimson et al., 2006).

A third approach is based on the growing number of case studies, ethical reviews, and documentary information now available with respect to industries that have an important stake in products that affect public health (Brennan et al., 2006; Hirshhorn et al., 2001; Rampton \& Stauber, 2002; Rundall, 1998). This approach avoids categorical recommendations to either allow or discourage relationships between science and industry in favor of a more-nuanced set of guidelines that outlines conditions of cooperation between science and industry (Adams, 2007).

\section{PERIL}

Adams' (2007) PERIL framework (purpose, extent, relevant harm, identifiers, link) provides a structured means of evaluating individual situations from an ethical perspective. Depending on circumstances, each of the five PERIL subcontinuums is influenced in varying ways by the different domains of risk.

Purpose refers to the degree to which purposes are divergent between funder and recipient. For example, if the primary purpose of the recipient is the advancement of public good, receiving funds from dangerous consumption industries such as tobacco, alcohol, and gambling companies will probably conflict with this purpose. Similarly, the risk is mitigated partially if the funder has a clear public-good role. For example, the provincial government of Ontario runs a state monopoly on liquor distribution, the profits from which they invest in a broad range of research (Adams, 2007). 
Extent is the degree to which the recipient relies on this source of funding. As the proportion of income increases, it becomes more difficult to separate one's research from expectations associated with the source. For example, a young investigator may find an award from an industry-sponsored organization is the sole source of salary support, which could create pressure to obtain industryfavorable results to ensure the continuation of funding.

Relevant harm is the degree of harm associated with this form of consumption. The level of harm generated by different forms of consumption varies. Lower potency products, such as lottery tickets or low-alcohol beer, are on the whole less likely to lead to problems than more-potent products, such as electronic gambling machines or alcoholic energy drinks.

Funders are unlikely to contribute anonymously, because for them the point of the exercise is often to be identified, to form a visible association with public-good activities for the purposes of positive branding. This in turn can be used for political or commercial purposes. The extent of visible association can be reduced by moving away from high-profile advertisements (such as media releases of findings) to more-discrete acknowledgements on plaques or at the end of publications. Through reputational risk, this strategy indirectly discourages engaging in industry-supported research.

The more direct the link is between funder and researcher, the stronger the influence and the more visible the association are. For example, direct funding by a tobacco company involves more exposure than receiving the funding via an independent intermediary agency, such as a foundation or governmental funding body. As long as there are no major competing interests for the intermediary agency, the separation reduces the likelihood that recipients will feel obligations, even coercion, for their activities to comply with the interests of the donor. The overall extent of moral jeopardy ranges from very high levels, as indicated by high ratings on all five subcontinuums, to very low levels, as indicated by consistently low ratings. Decisions regarding future industry relationships are made accordingly. Boxes 16.7 and 16.8 provide two case studies to illustrate how a PERIL analysis can be applied to specific funding opportunities.

\section{Is Industry Funding of Research the only Peril that Matters?}

A new genre of policy analysis suggests that vested interests use research to achieve their ultimate goals of profit maximization (Babor \& Robaina, 2013).

In their illuminating series of articles, Hawkins, McCambridge and colleagues highlight the way in which the alcohol industry uses both industryfunded research and their relationships with researchers to demonstrate their credibility and good intentions (Hawkins \& Holden, 2014; Hawkins et al., 2012; McCambrige et al., 2013; Hawkins \& Holden, 2014). These public-relations activities are commonly hidden in the rhetoric of corporate social responsibility, which is particularly important to recognize when considering the long-term 
relationships between the alcohol industry and most politicians and the way in which these relationships are formed. Although politicians might read a newspaper article about new alcohol trends, they are easily calmed when their likeable industry representative, who knows their kids' names and the schools they go to, assures them that there is no need to worry because the industry often through one of its front bodies such as Drinkwise (Australia), Drinkaware (United Kingdom), EURAB (Europe), or the ABMRF/The Foundation for Alcohol Research (United States) - is working with a group of respected researchers to deal with the issue. Hawkins and Holden (2014) demonstrated convincingly just how effective this strategy is, especially when it is combined with the very long-term engagement approach that the alcohol industry adopts with politicians from all sides of the political fence. It is even more effective when they are able to suggest that the industry has actually funded the research into this important issue and that they have found it not to be so important or that the interventions they recommend are effective and much more palatable politically than "nanny state" interventions, such as raising taxes or restricting trading hours (Miller et al., 2011).

In the end, whether or not other elements of the PERIL analysis such as reputational risk or extent of funding are of concern, the overriding consideration in the strategic funding of research by the alcohol industry is their ability to use those relationships to gain a place at the discussion table regarding policy at the state, federal, and global levels.

A university-based school of medicine distributes an email announcing to all faculty and staff the availability of a new research funding opportunity. The announcement reads: "Please see the link below for an available funding opportunity from the Philip Morris External Research Foundation The website invited scientists to submit funding proposals to Philip Morris's independent, peer-reviewed, external research program, which is willing to support research on the disease mechanisms and health endpoints of tobacco smoking and smoke exposure. The program's scientific advisory board members are listed on one of the pages of the request for applications, an impressive-looking group of academics, including department chairs, distinguished professors, and even the President of the Hungarian Academy of Sciences. This announcement raises a number of questions about the moral hazards of industry sponsorship of scientific research.

Assume you are a tobacco researcher at a large academic medical center whose dissertation was recently completed on a topic related to the announcement. Should you apply for the funds? A PERIL analysis along the lines recommended in the Adams article would require some 
independent research and a review of the literature on tobacco-industry tactics.

\section{PERIL Analysis}

Is the purpose of your academic institution (e.g., "excellent medical care through research and education") consistent with the stated purpose of Phillip Morris (i.e., to sell cigarettes to adults, without taking any responsibility for the millions of adolescents who become addicted before they can legally purchase tobacco products)? If your institution is in any way devoted to health, the answer is that the purposes are incompatible. In addition, some have pointed to the anti-scientific record of Phillip Morris. The reason Phillip Morris's research foundation is now called "external" is that the company was ordered to disband a prior organization that was found by a U.S. court to be biased in the way it awarded grants to scientists.

What about the extent of the funding? Is it sufficient to compromise the independence of an academic medical center with a large portfolio of research grants and contracts? It probably is not, but for individual investigators it could create a dependence on tobacco money when other sources of funding become more scarce.

Is there relevant harm associated with Phillip Morris's continued marketing of tobacco products? The evidence is incontrovertible.

Will the recipient of the funds be identified with the funder so that Phillip Morris might benefit from its support of university-based scientists? And could funded scientists eventually be exposed to reputational risk if their names were associated with Phillip Morris? The answer is a possible yes to both questions.

Finally, is the nature of the link between recipient and donor direct or indirect? In this case it is indirect; therefore, it may not involve a major competing interest, and there are no limitations on publication imposed by the funder.

In summary, the analysis indicates that there are incompatible institutional interests, a potential for developing dependence on an industry funding source, relevant harms to the public if tobacco sales continue as more research is conducted, a potential for future reputational risk, and a possible political benefit for Phillip Morris.

Box 16.7: PERIL analysis of a funding opportunity from Phillip Morris. 
A residential rehabilitation charity approaches you to collaborate in an application to fund doctoral research into the long-term effectiveness of its project. The charity reports that it has been involved in research previously and has found it beneficial. The methodology is discussed and agreed. The application is designed to go to a governmental funding body that provides matching funds for collaborations between community organizations and universities. The charity expresses concern about the confidentiality of its service users and requests that "We would, however, want the research findings to be kept confidential except in so far as they are needed to fulfill the requirements for the degree." Subsequent investigation shows that, although the charity refers to a strong research pedigree, findings have been published only in non-peerreviewed trade magazines or internal reports.

\section{PERIL Analysis}

Is the purpose of your academic institution (e.g., excellent medical care through research and education) consistent with the stated purpose of the charity? At first glance it would appear that the charity has the laudable goal of assessing its effectiveness through independent research. However, its desire to control dissemination (presumably in case of unfavorable findings) and its previous track record of publishing only in non-peerreviewed journals would suggest that its goal might not be excellence.

What about the extent of the funding? In this example, this is unlikely to be a major factor because the amount involved would be comparatively small.

Is there relevant harm? There is a chance of some harm in this case if the findings are unfavorable and the charity chooses not to disseminate the report. In this situation, the charity is clearly providing ineffective treatment and using resources that might be better used elsewhere. In addition, it may be skewing the knowledge base through omission of negative findings.

There is also a significant issue that the researchers and university will be identified with the evaluation. It is within the interest of the charity to point to the fact that the research was independently conducted.

Finally, is the nature of the link between recipient and donor direct or indirect? In this case it is indirect; therefore, it may not involve a major competing interest, and there are no limitations on publication imposed by the funder. In this case, it would be possible for the researchers or the 
university to insist that the charity remove its right to control release of the data. If that were done, the PERIL analysis would suggest that the funding is worth pursuing.

Box 16.8: PERIL analysis of a funding opportunity limited by conditions imposed by a collaborating organization.

\section{Conclusion}

Every individual, discipline, and funding organization brings its own agenda to the research process. The practical and ethical conundrums associated with research funding are becoming increasingly complex in a context in which research plays a greater role in the regulation and marketing of potentially addictive products. The examples reviewed in this chapter suggest that addiction scientists should be vigilant and critically reflective about the funding they accept from any source, particularly in relation to the ultimate purpose of such funding. This is even more so the case when there are restrictions on the design, interpretation, and publication of the resulting data. Thus, researchers should always be very wary about accepting research funding directly from dangerous consumption industries, their trade associations, and public-relations organizations. Consulting arrangements wherein scientists are paid by parties with a clear competing interest to critique the work of other scientists can constitute a serious financial competing interest that is unlikely to benefit either science or the investigator. Acceptance of fees for writing book chapters, preparing background reports, attending industry-organized conferences, and writing letters to the editor should be prefaced by careful consideration of the following questions:

(1) To what extent is the scientific activity designed to promote the commercial interests of a particular industry?

(2) Will the funding source be acknowledged?

(3) How could this research or my institution's relationship with this company be used to undermine the implementation of effective policy?

Addiction scientists also need to be careful that their objectivity and independence are not compromised by fraternizing with industry executives as well as paid travel to meeting sites and consulting fees (Wagner \& Steinzor, 2007). Investigators in particular need to be attentive to the possibility that industry funding in many health areas is being contested on both ethical and scientific grounds (Foxcroft, 2005; King, 2006; Brennan et al., 2006). Finally, researchers 
should examine all funding sources using a framework such as the PERIL analysis, which allows the individual scientist and his or her institution to review relevant information about the motives of the funding source and the uses of the research that will be conducted.

Please visit the website of the International Society of Addiction Journal Editors (ISAJE) at www.isaje.net to access supplementary materials related to this chapter. Materials include additional reading, exercises, examples, PowerPoint presentations, videos, and e-learning lessons.

\section{References}

Adair, J. G. (1995). The research environment in developing countries: Contributing to the national development of discipline. International Journal of Psychology, 30, 643-662.

Adams, P. J. (2007). Assessing whether to receive funding support from tobacco, alcohol, gambling and other dangerous consumption industries. Addiction, 102, 1027-1033.

Adams, P. J., \& Rossen, F. (2006). Reducing the moral jeopardy associated with receiving funds from the proceeds of gambling. Journal of Gambling Issues, 17, 1-21.

Ashcroft, R. E. (2006). Getting what you pay for? The ethics of selective publication. International Journal of Drug Policy, 17, 238-239.

Babor, T. F. (2006). Diageo, University College Dublin and the integrity of alcohol science: It's time to draw the line between public health and public relations. Addiction, 101, 1375-1377.

Babor, T. F. (2009). Alcohol research and the alcoholic beverage industry issues, concerns and conflicts of interest. Addiction, 104, 34-47.

Babor, T. F., Edwards, G., \& Stockwell, T. (1996). Science and the drinks industry: Cause for concern. Addiction, 91, 5-9.

Babor, T. F., \& McGovern, T. F. (2007). Minimizing moral jeopardy: Perils of the slippery slope. Addiction, 102, 1037-1038.

Babor, T., \& Miller, P. (2014). McCarthyism, conflict of interest and Addiction's new transparency declaration procedures. Addiction, 109, 341-344.

Babor, T. F., \& Robaina, K. (2013). Public health, academic medicine, and the alcohol industry's corporate social responsibility activities. American Journal of Public Health, 103, 206-214.

Babor, T. F., \& Xuan, Z. (2004). Alcohol policy research and the grey literature. Nordic Studies on Alcohol and Drugs, 125-137.

Bhutta, A. (2002). Ethics in international health research: A perspective from the developing world. Bulletin of the World Health Organization, $80,114-120$. 
Brennan, T. A., Rothman, D. J., Blank, L., Blumenthal, D., Chimonas, S. C., Cohen, J. J., . . ., Smelser, N. (2006). Health industry practices that create conflicts of interest: A policy proposal for academic medical centers. JAMA, 295, 429-433.

Caetano, R. (2008). About smoke and mirrors: The alcohol industry and the promotion of science. Addiction, 103, 175-178.

Carpenter, C. M., Wayne, G. F., \& Connolly, G. N. (2005). Designing cigarettes for women: New findings from the tobacco industry documents. Addiction, $100,837-851$.

Clarke, J. (2007). Religion as a competing interest. Medical Journal of Australia, $187,421-422$.

Collier, P. (2007). The bottom billion: Why the poorest countries are failing and what can be done about it. New York, NY: Oxford University Press.

Dench, S., Iphofen, R., \& Huws, U. (2004). RESPECT code of practice for socio-economic research. Brighton, UK: Institute for Employment Studies. Retrieved from http://www.respectproject.org/code/respect_code.pdf.

Drope, J., Bialous, S. A., \& Glantz, S. A. (2004). Tobacco industry efforts to present ventilation as an alternative to smoke-free environments in North America. Tobacco Control, 13(Supplement 1), i41-i47.

Edwards, G., West, R., Babor, T. F., Hall, W., \& Marsden, J. (2005). The integrity of the science base: A test case. Addiction, 100, 581-584.

Einstein, A. (1934). The world as I see it. Forum and Century: Living Philosophies, 84, 193-194.

Etter, J.-F., Burri, M., \& Stapleton, J. (2007). The impact of pharmaceutical company funding on results of randomized trials of nicotine replacement therapy for smoking cessation: A meta-analysis. Addiction, 102, 815-822.

Federation of American Societies for Experimental Biology. Federation of American Societies for Experimental Biology Toolkit 2015 [20 Sep 2015]. Available from: http://www.webcitation.org/6bgp0m2Ap.

Fischer, B., Jones, W., Krahn, M., \& Rehm, J. (2011). Differences and overtime changes in levels of prescription opioid analgesic dispensing from retail pharmacies in Canada, 2005-2010. Pharmacoepidemiology and Drug Safety, 20(12), 1269-1277.

Fischer, B., Keates, A., Bühringer, G., Reimer, J., \& Rehm, J. (2013). Nonmedical use of prescription opioids and prescription opioid-related harms: why so markedly higher in North America compared to the rest of the world? Addiction, 109(2), 177-181.

Foxcroft, D. (2005). International Center for Alcohol Policies (ICAP)'s latest report on alcohol education: A flawed peer review process. Addiction, 100, 1066-1068.

Friedman, L. S., \& Richter, E. D. (2004). Relationship between conflicts of interest and research results. Journal of General Internal Medicine, 19, 51-56.

Gmel, G., Heeb, J. L., \& Rehm, J. (2003). Research and the alcohol industry [Letter to the editor]. Addiction, 98, 1773-1774. 
Gruning, T., Gilmore, A. B., \& McKee, M. (2006). Tobacco industry influence on science and scientists in Germany. American Journal of Public Health, 96, 20-32.

Gupta, R., \& Derevensky, J. L. (1998). Adolescent gambling behavior: A prevalence study and examination of the correlates associated with problem gambling. Journal of Gambling Studies, 14, 319-345.

Hall, W. (2006a). Ensuring that addiction science is deserving of public trust. Addiction, 101, 1223-1224.

Hall, W. (2006b). Minimising research censorship by government funders. International Journal of Drug Policy, 17, 240-241.

Hawkins, B., \& Holden, C. (2014). 'Water dripping on stone'? Industry lobbying and UK alcohol policy. Policy \& Politics, 42, 55-70.

Hawkins, B., Holden, C., \& McCambridge, J. (2012). Alcohol industry influence on UK alcohol policy: A new research agenda for public health. Critical Public Health, 22, 297-305.

Haworth, A., \& Simpson, R. (Eds.). (2004). Moonshine markets: Issues in unrecorded alcohol beverage production and consumption. Florence, KY: BrunnerRoutledge.

Hirshhorn, N., Aguinaga-Bialous, S., \& Shatenstein, S. (2001). Philip Morris' new scientific initiative: An analysis. Tobacco Control, 10, 247-252.

Hough, M., \& Turnbull, P. (2006). Over-regulation or legitimate control? International Journal of Drug Policy, 17, 242-243.

Iida, K., \& Proctor, R. N. (2004). Learning from Philip Morris: Japan Tobacco's strategies regarding evidence of tobacco health harms as revealed in internal documents from the American tobacco industry. The Lancet, 363, 1820-1824.

Jantos, M., \& Kiat, H. (2007). Prayer as medicine: How much have we learned? Medical Journal of Australia, 186(Supplement), S51-S53.

Kassirer, J. P. (2005). On the take: How medicine's complicity with big business can endanger your health. New York, NY: Oxford University Press.

Khoshnood, K. (2006). The regulation of research by funding bodies: A wakeup call. International Journal of Drug Policy, 17, 246-247.

King, J. (2006). Accepting tobacco industry money for research: Has anything changed now that harm reduction is on the agenda? Addiction, 101, 1067-1069.

Kraus, L., Pabst, A., Piontek, D., \& Gomes de Matos, E. (2013). Substanzkonsum und substanzbezogene Störungen: Trends in Deutschland 1980-2012 [Consumption of substances and substance-related disorders: Trends in Germany 1980-2012]. SUCHT, 59(6), 333-345.

Lenton, S., \& Midford, R. (2006). Research regulation by omission and by publication. International Journal of Drug Policy, 17, 244-245.

McCambridge, J., Hawkins, B., \& Holden, C. (2013). Industry use of evidence to influence alcohol policy: A case study of submissions to the 2008 Scottish government consultation. PLoS Medicine, 10(4), e1001431. 
McCreanor, T., Casswell, S., \& Hill, L. (2000). ICAP and the perils of partnership. Addiction, 95, 179-185.

Miller, P. (2013). Energy drinks and alcohol: Research supported by industry may be downplaying harms. BMJ, 347, f5345. DOI: https://doi.org/10.1136/ bmj.f5345

Miller, P. G., Groot, F. d., McKenzie, S., \& Droste, N. (2011). Alcohol industry use of social aspect public relations organisations against preventative health measures. Addiction, 106, 1560-1567.

Miller, P. G., Moore, D., \& Strang, J. (2006). The regulation of research by funding bodies: An emerging ethical issue for the alcohol and other drug sector. International Journal of Drug Policy, 17, 12-16.

Muggli, M. E., LeGresley, E. M., \& Hurt, R. D. (2004). Big tobacco is watching: British American Tobacco's surveillance and information concealment at the Guildford depository. The Lancet, 363, 1812-1819.

Munro, G. (2004). An addiction agency's collaboration with the drinks industry: MooJoose as a case study. Addiction, 99, 1370-1374.

Obot, I. S. (2004). Responding to drug problems in Nigeria: The role of civil society organizations. Substance Use and Misuse, 39, 1289-1301.

Ong, E. K., \& Glantz, S. A. (2000). Tobacco industry efforts subverting International Agency for Research on Cancer's second-hand smoke study. The Lancet, 355, 1253-1259.

OpenSecrets.org. (2015). Global Alcohol Producers Group: OpenSecrets.org [20 Sep 2015]. Available from http://www.webcitation.org/6bgoUXaPE.

Parascandola, M. (2005). Science, industry, and tobacco harm reduction: A case study of tobacco industry scientists' involvement in the National Cancer Institute's Smoking and Health Program, 1964-1980. Public Health Reports, 120, 338-349.

Pollak, H. (2007, March). How should harm reduction interventions be evaluated? Paper presented at the International Society for the Study of Drug Policy, Oslo, Norway.

Rampton, S., \& Stauber, J. (2002). Research funding, conflicts of interest, and the meta-methodology of public relations. Public Health Reports, 117, $331-339$.

Room, R. (2005). Drinking patterns as an ideology. Addiction, 100, 1803-1804.

Rundall, P. (1998). Should industry sponsor research? How much research in infant feeding comes from unethical marketing? BMJ, 317, 338-339.

Savell, E., Gilmore, A. B., \& Fooks, G. (2014). How does the tobacco industry attempt to influence marketing regulations? A systematic review. PLoS ONE, 9(2), e87389.

Singer, M. (2008). Drugging the poor: Legal and illegal drugs and social inequality. Long Grove, IL: Waveland Press.

Small, D., \& Drucker, E. (2006). Policy makers ignoring science and scientists ignoring policy: The medical ethical challenges of heroin treatment. Harm Reduction Journal, 3, 16. 
Stenius, K., \& Babor, T. F. (2010). The alcohol industry and public interest science. Addiction, 105, 191-198.

Stimson, G., Grant, M., Choquet, M., \& Garrison, P. (2006). Drinking in context: Patterns, interventions, and partnerships. Washington, DC: Routledge.

Wagner, W., \& Steinzor, R. (Eds.). (2007). Rescuing science from politics: Regulation and the distortion of scientific research. New York, NY: Cambridge University Press.

Wander, N., \& Malone, R. E. (2006). Making big tobacco give in: You lose, they win. American Journal of Public Health, 96, 2048-2054.

White, W. L., \& Popovits, R. M. (2001). Critical incidents: Ethical issues in the prevention and treatment of addiction (2nd ed.). Bloomington, IL: Chestnut Health Systems.

Willis, E. (1989). Medical dominance: The division of labour in Australian health care (Rev. ed.). Sydney, Australia: Allen \& Unwin.

Wilton, R., \& DeVerteuil, G. (2006). Spaces of sobriety/sites of power: Examining social model alcohol recovery programs as therapeutic landscapes. Social Science \& Medicine, 63, 649-661. 